\title{
Effect of Ni Doping on Strength and Damping Capacity of Fe-Al Alloys
}

\author{
Hiroyuki Y. YASUDA, ${ }^{*}$ Kouki FUKUSHIMA, Keiji KOUZAI and Taisuke EDAHIRO \\ Division of Materials and Manufacturing Science, Graduate School of Engineering, Osaka University, 2-1 Yamada-oka, Suita, \\ Osaka, 565-0871 Japan.
}

(Received on October 1, 2012; accepted on January 7, 2013)

\begin{abstract}
Strength and damping capacity of Fe-Al alloys doped with different amounts of Ni were examined. FeAl alloys with an appropriate amount of $\mathrm{Ni}$ doping exhibited yield stress higher than $1 \mathrm{GPa}$ and internal friction of above 0.032. In these alloys, the NiAl phase with the B2 structure densely precipitated in the Fe-Al matrix, satisfying the cube-on-cube orientation relationship. The precipitation of NiAl resulted in high strength, which was associated with the difference in primary slip systems between the NiAl precipitates and the Fe-Al matrix. Moreover, the internal friction measured under an external magnetic field showed low values, suggesting that $\mathrm{Fe}-\mathrm{Al}$ alloys with the NiAl precipitates demonstrated magneto-mechanical damping caused by the irreversible motion of magnetic domain walls. The Al concentration in the Fe-Al matrix became appropriate for damping properties by the precipitation of NiAl, resulting in an increase in the internal friction of the alloy.
\end{abstract}

KEY WORDS: internal friction; damping materials; particle strengthening; magneto-mechanical damping.

\section{Introduction}

The development of damping materials with high strength and damping capacity has attracted much attention, especially for automobile and seismic applications. ${ }^{1-4)}$ For instance, high strength above $1 \mathrm{GPa}$ and internal friction $\left(Q^{-1}\right)$ above 0.032 are required for practical application to a vibration source of automobiles, such as engines and gears. ${ }^{2)}$ Recently, $\mathrm{Fe}-\mathrm{Al}$ alloys with $16-18$ at\%Al have been expected as damping materials to absorb the vibration and noise due to their high damping capacity. ${ }^{5,6}$ These $\mathrm{Fe}-\mathrm{Al}$ alloys have been successfully developed and are commercially available in Japan now. At low strain amplitudes and ambient temperature, the high damping capacity of $\mathrm{Fe}-\mathrm{Al}$ alloys is usually attributed to the magneto-mechanical damping associated with the irreversible motion of magnetic domain walls. ${ }^{5-12)}$ However, the ultimate tensile strength of binary $\mathrm{Fe}-\mathrm{Al}$ alloys was approximately $500 \mathrm{MPa}$, not enough to use the alloys to the automobile vibration sources.

In general, in conventional damping materials, there is a trade-off between the strength and damping capacity and therefore, it is difficult to obtain materials that exhibit both high strength and high damping capacity. In the present study, however, we found that small amount of $\mathrm{Ni}$ doping to $\mathrm{Fe}-\mathrm{Al}$ alloys increased not only the yield stress $\left(\sigma_{\mathrm{y}}\right)$ but also the $Q^{-1}$ and consequently, $\sigma_{\mathrm{y}}>1 \mathrm{GPa}$ and $Q^{-1}>0.032$ could be achieved by optimizing the chemical composition. In this paper, we report the effect of $\mathrm{Ni}$ doping on the

* Corresponding author: E-mail: hyyasuda@mat.eng.osaka-u.ac.jp DOI: http://dx.doi.org/10.2355/isijinternational.53.704 strength and damping capacity of $\mathrm{Fe}-\mathrm{Al}$ alloys. In addition, the strengthening and damping mechanisms in Ni-doped $\mathrm{Fe}-\mathrm{Al}$ alloys will also be discussed.

\section{Experimental Procedure}

Master ingots of Fe-16.0-25.0Al (at\%) doped with 0 $10.0 \mathrm{Ni}$ were prepared by melting high purity elements in a plasma arc furnace in a purified Ar atmosphere. The chemical compositions selected in the present study are plotted in the isothermal section of $\mathrm{Fe}-\mathrm{Al}-\mathrm{Ni}$ ternary phase diagram at $750^{\circ} \mathrm{C}$ as shown in Fig. 1. ${ }^{13)}$ Note that most of selected chemical compositions were located near the $\alpha-\beta^{\prime}$ twophase field. The $\alpha$ and $\beta^{\prime}$ phases are the $\mathrm{Fe}-\mathrm{Al}$ solid solution and NiAl with the bcc and B2 structures, respectively. After homogenization at $1100^{\circ} \mathrm{C}$ for $48 \mathrm{~h}$, the specimens were

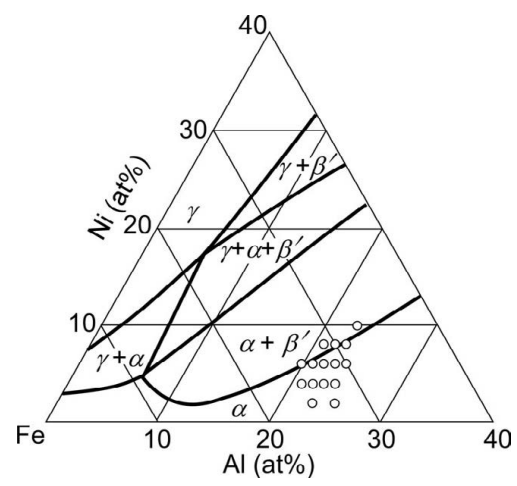

Fig. 1. Fe-Al-Ni ternary phase diagram at $750{ }^{\circ} \mathrm{C}^{13)}$ and chemical compositions of the alloys prepared in the present study. 

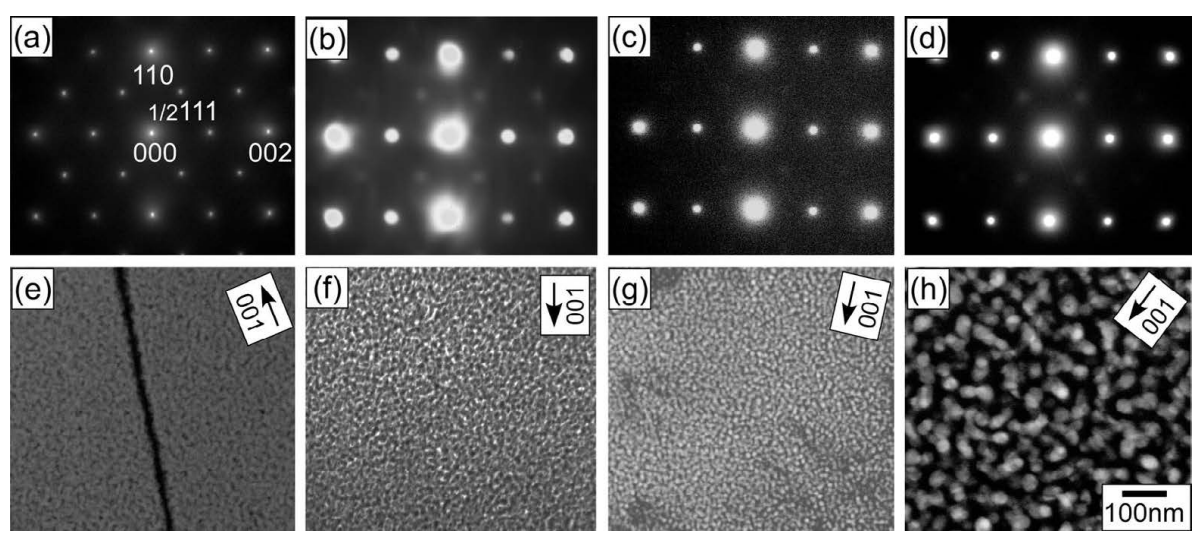

Fig. 2. [1 10$]$ SAED patterns ((a)-(d)) and DF images ((e)-(h)) of Fe-23.0Al- $x \mathrm{Ni}$ alloys. DF images were taken with 001 reflection. (a), (e) $x=2.0$, (b), (f) $x=4.0$, (c), (g) $x=6.0$ and (d), (h) $x=8.0$.

slowly cooled to room temperature at $80^{\circ} \mathrm{C} / \mathrm{h}$. The microstructure of $\mathrm{Fe}-\mathrm{Al}-\mathrm{Ni}$ alloys was observed using a transmission electron microscope (TEM) operated at $300 \mathrm{kV}$. The plane and direction of TEM observation were indexed with respect to the bcc structure.

Rectangular specimens of which dimension is $2 \times 2 \times 5 \mathrm{~mm}^{3}$ were cut from $\mathrm{Fe}-\mathrm{Al}-\mathrm{Ni}$ ingots by spark machining. These specimens were mechanically and electrolytically polished to remove surface damage. Compression tests were performed in air at room temperature at an initial strain rate of $1.7 \times 10^{-4} \mathrm{~s}^{-1}$.

The $Q^{-1}$ values of $\mathrm{Fe}-\mathrm{Al}-\mathrm{Ni}$ alloys were measured with a dynamical mechanical analyzer (DMA) equipped with a single cantilever module at strain amplitudes $(\varepsilon)$ ranging between $10^{-4}$ and $5 \times 10^{-3}$. The DMA cyclically bent the cantilever plates of $\mathrm{Fe}-\mathrm{Al}-\mathrm{Ni}$ alloys and could directly measure the phase shift $(\phi)$ between the force and displacement signals. The $Q^{-1}$ value is given by the following equation,

$$
Q^{-1}=\tan \phi
$$

Measurement of $Q^{-1}$ was conducted at room temperature at a frequency $(f)$ of $1 \mathrm{~Hz}$. In order to examine the damping mechanism of Ni-doped specimens, the $Q^{-1}$ was also measured by a free decay method under an external magnetic field of $0.25 \mathrm{~T}$; the details of the method are described in a previous paper. ${ }^{12)}$ The dimension and shape of the cantilever specimens for the free-decay method were the same as those for the DMA measurement. The specimens were bent at a resonance frequency of about $1050 \mathrm{~Hz}$ and were released. The decay of free vibration was recorded by a laser displacement meter.

It is well known that magnetostriction is closely related to magneto-mechanical damping. ${ }^{14)}$ The magnetostriction $\left(\lambda_{\mathrm{m}}\right)$ of $\mathrm{Fe}-\mathrm{Al}-\mathrm{Ni}$ alloys with $0,2.0$ and $6.0 \mathrm{at} \% \mathrm{Ni}$ was measured using a strain gauge method. A non-magnetoresistive strain gauge was put on the alloys. It is also noted that a dummy gauge was put on a non-magnetic sample to cancel the magnetoresistance effect. Magnetic field of $0.8 \mathrm{MA} / \mathrm{m}$ was applied to $\mathrm{Fe}-\mathrm{Al}-\mathrm{Ni}$ alloys at room temperature and the magnetostriction parallel to the field was measured.

\section{Results}

\subsection{Microstructure of $\mathrm{Fe}-\mathrm{Al}-\mathrm{Ni}$ Alloys}

Figure 2 shows the selected area electron diffraction (SAED) patterns and dark-field (DF) images of Fe-23.0Al-

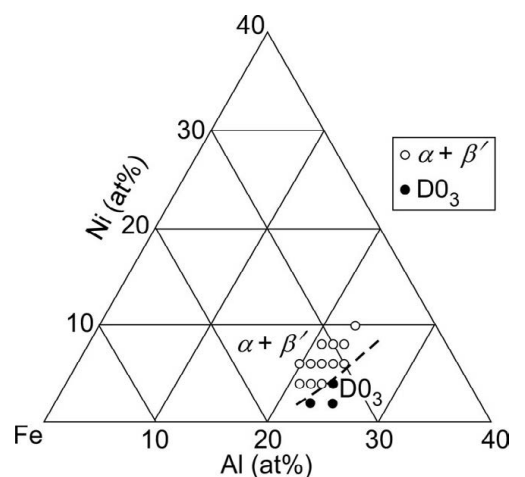

Fig. 3. Phase constituents of Fe-Al-Ni alloys slowly cooled to room temperature at $80^{\circ} \mathrm{C} / \mathrm{h}$.

2.0-8.0Ni alloys, taken by the TEM. In Fe-23.0Al-2.0Ni alloys, both $1 / 2111$ and 001 superlattice spots can be seen and a typical $\mathrm{D}_{3}$ ordered domain structure develops in the DF image taken with 001 reflection (Figs. 2(a), 2(e)). In contrast, at and above $4.0 \mathrm{at} \% \mathrm{Ni}, 1 / 2111$ reflection becomes diffuse while 001 reflection is clearly visible as shown in Figs. 2(b)-2(d). Moreover, in the DF images with 001 reflection, precipitation of the $\beta^{\prime}$-NiAl phase with the B2 structure can be observed in the $\alpha$-Fe-Al matrix (Figs. 2(f)$2(\mathrm{~h})$ ). Moreover, the amount of the $\beta^{\prime}$ precipitates increases with increasing Ni content. From the SAED patterns, the $\alpha$ and $\beta^{\prime}$ phases satisfy the cube-on-cube orientation relationship. In addition, there is no misfit dislocation between the $\alpha$ and $\beta^{\prime}$ phases, suggesting that these phases are coherent. Moreover, the diffuse $1 / 2111$ reflection at and above 4.0 at $\% \mathrm{Ni}$ suggests that a short-range order develops in the $\alpha$ matrix. ${ }^{4)}$ Figure 3 shows the phase constituent of $\mathrm{Fe}-\mathrm{Al}-$ Ni alloys prepared in the present study. The $\alpha-\beta^{\prime}$ two-phase field extends over wide chemical compositions, which is fairly consistent with $\mathrm{Fe}-\mathrm{Al}-\mathrm{Ni}$ phase diagram shown in Fig. 1. It should be noted that $\mathrm{Fe}-\mathrm{Al}-\mathrm{Ni}$ alloys prepared in the present study were slowly cooled to room temperature after homogenization at $1100^{\circ} \mathrm{C}$. Since the ternary $\mathrm{Fe}-\mathrm{Al}-$ Ni phase diagram shown in Fig. 1 was determined at $750^{\circ} \mathrm{C}$, the $\alpha-\beta^{\prime}$ two-phase field in the slowly cooled alloys becomes wider than that at $750^{\circ} \mathrm{C}$.

3.2. Strength and Damping Capacity of $\mathrm{Fe}-\mathrm{Al}-\mathrm{Ni}$ Alloys

Figure 4 shows the stress-strain curves of Fe-23.0Al$2.0-10.0 \mathrm{Ni}$ alloys compressed at room temperature. $\mathrm{Fe}-$ 


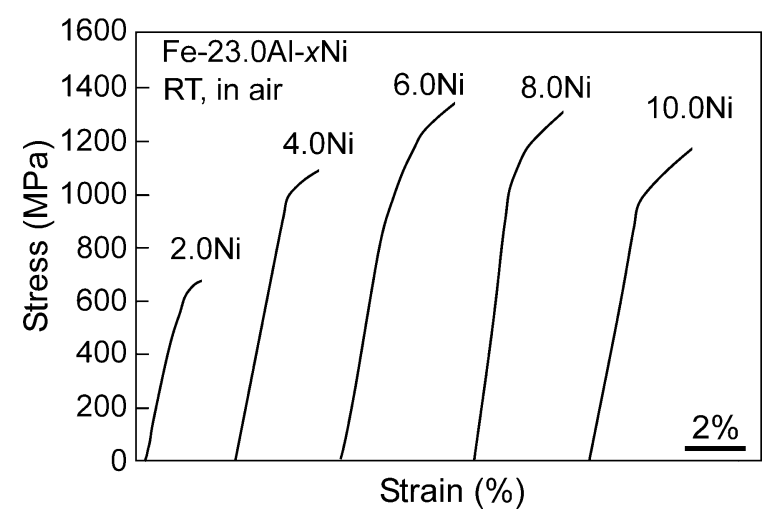

Fig. 4. Stress-strain curves of $\mathrm{Fe}-23.0 \mathrm{Al}-2.0-10.0 \mathrm{Ni}$ alloys compressed at room temperature.

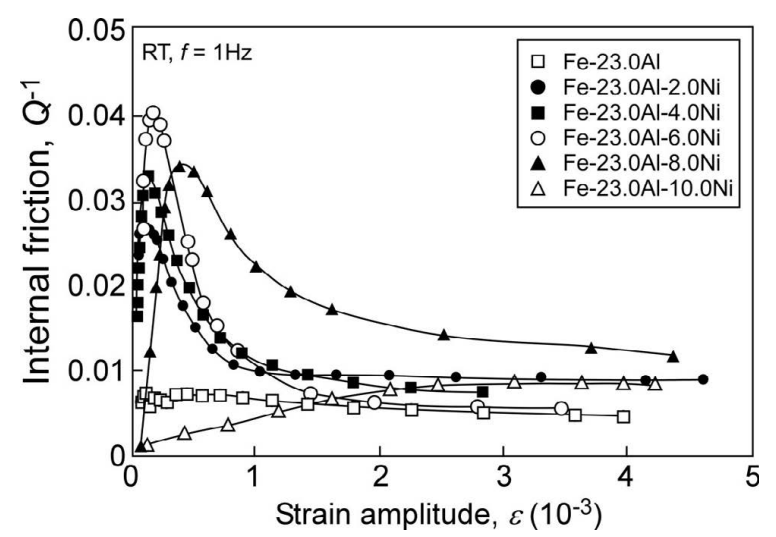

Fig. 5. $\varepsilon$ dependence of $Q^{-1}$ in $\mathrm{Fe}-23.0 \mathrm{Al}-0-10.0 \mathrm{Ni}$ alloys at room temperature; $f=1 \mathrm{~Hz}$.

23.0Al binary alloys exhibit a yield stress $\left(\sigma_{\mathrm{y}}\right)$ of about $570 \mathrm{MPa}$. The $\sigma_{\mathrm{y}}$ increases with increasing amount of $\mathrm{Ni}$ doping and exceeds $1 \mathrm{GPa}$ at and above 4.0 at $\% \mathrm{Ni}$. As shown in Fig. 2, the $\beta^{\prime}$-NiAl phase also precipitated at and above 4.0 at $\% \mathrm{Ni}$. This means that strengthening by Ni doping in $\mathrm{Fe}-\mathrm{Al}$ alloys is closely related to the $\beta^{\prime}$-NiAl precipitation. Variation in $Q^{-1}$ with $\varepsilon$ in $\mathrm{Fe}-23.0 \mathrm{Al}-0-10.0 \mathrm{Ni}$ alloys is shown in Fig. 5. Binary $\mathrm{Fe}-23.0 \mathrm{Al}$ and ternary $\mathrm{Fe}-$ 23.0Al-10.0Ni alloys demonstrate low $Q^{-1}$ values in the wide $\varepsilon$ range. However, the $Q^{-1}$ in $\mathrm{Fe}-23.0 \mathrm{Al}-2.0-8.0 \mathrm{Ni}$ alloys increases rapidly with increasing $\varepsilon$ up to about $1 \times 10^{-4}$. After showing a peak, further increase in $\varepsilon$ results in a decrease in $Q^{-1}$ followed by the saturation. The $\varepsilon$ dependence of $Q^{-1}$ in the alloys is in good agreement with magneto-mechanical damping. ${ }^{5-11)}$ Moreover, the peak value of $Q^{-1}\left(Q^{-1} \max \right)$ at $\mathrm{Ni}$ contents between 4.0 at $\%$ and 8.0 at $\%$ exceeds 0.032 .

Figure 6 shows change in $\sigma_{\mathrm{y}}$ and $Q^{-1}{ }_{\text {max }}$ with amount of $\mathrm{Ni}$ in alloys containing $23.0 \mathrm{at} \% \mathrm{Al}$. Both $\sigma_{\mathrm{y}}$ and $Q^{-1}{ }_{\max }$ rise abruptly at around 4.0 at $\% \mathrm{Ni}$ and remain almost constant up to 8.0 at $\% \mathrm{Ni}$. The precipitation of $\beta^{\prime}$-NiAl started around 4.0 at $\% \mathrm{Ni}$, suggesting that the strength and damping capacity of $\mathrm{Fe}-\mathrm{Al}-\mathrm{Ni}$ alloys are closely related to the $\beta^{\prime}$ precipitation. However, further increase in Ni content results in a decrease in $Q^{-1}$ max though the $\sigma_{\mathrm{y}}$ remains almost constant at and above 4.0 at $\% \mathrm{Ni}$. Hence, appropriate amounts of $\mathrm{Ni}$ doping were found to be effective in the increase in both $\sigma_{\mathrm{y}}$ and $Q^{-1}$.

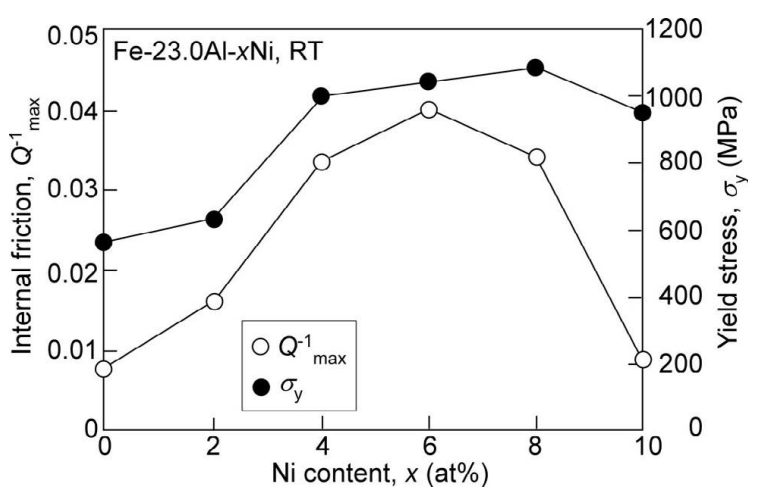

Fig. 6. Variation in $\sigma_{\mathrm{y}}$ and $Q^{-1}$ max with amount of $\mathrm{Ni}$ in alloys containing 23.0 at $\% \mathrm{Al}$; at room temperature, $f=1 \mathrm{~Hz}$.

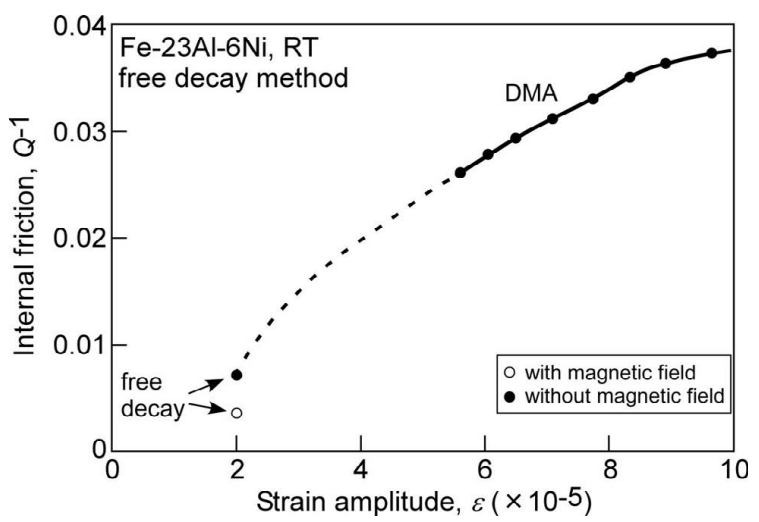

Fig. 7. Variation in $Q^{-1}$ with $\varepsilon$ in Fe-23.0Al-6.0Ni alloys at room temperature with or without magnetic field; free decay method, at a resonance frequency of about $1050 \mathrm{~Hz}$.

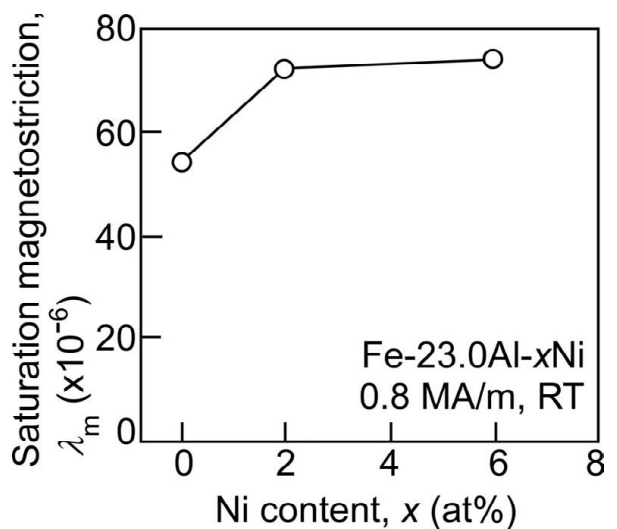

Fig. 8. Saturation magnetostriction of $\mathrm{Fe}-23.0 \mathrm{Al}-x \mathrm{Ni}$ alloys $(x=$ $0,2.0$ and 6.0), parallel to a magnetic field of $0.8 \mathrm{MA} / \mathrm{m}$ at room temperature.

\subsection{Behavior of Fe-Al-Ni Alloys under Magnetic Field}

In order to examine the damping mechanism, the $Q^{-1}$ was measured under a magnetic field of $0.25 \mathrm{~T}$. Figure 7 shows variation of $Q^{-1}$ with $\varepsilon$ in $\mathrm{Fe}-23.0 \mathrm{Al}-6.0 \mathrm{Ni}$ alloys, measured by a free decay method with or without magnetic field. At $\mathcal{E}=2 \times 10^{-5}$, the $Q^{-1}$ at zero magnetic field is much higher than that at $0.25 \mathrm{~T}$, suggesting that high damping capacity of $\mathrm{Fe}-\mathrm{Al}-\mathrm{Ni}$ alloys is caused by magneto-mechanical damping. It is well known that the magneto-mechanical damping depends on $\lambda_{\mathrm{m}}{ }^{14)}$ Thus, the $\lambda_{\mathrm{m}}$ measurement parallel to a magnetic field of $0.8 \mathrm{MA} / \mathrm{m}$ was also conducted as shown in Fig. 8. The $\lambda_{\mathrm{m}}$ of $\mathrm{Fe}-23.0 \mathrm{Al}-6.0 \mathrm{Ni}$ alloys is higher than 


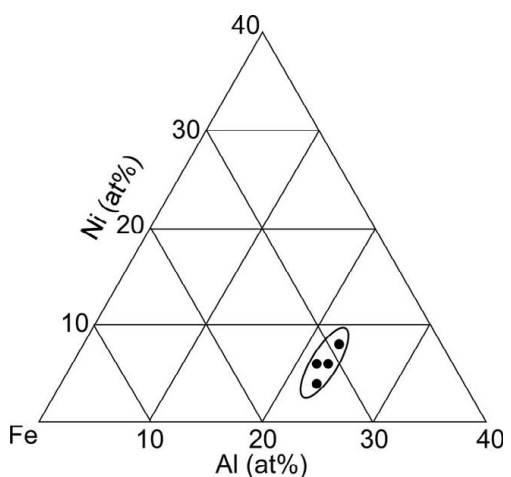

Fig. 9. Chemical compositions of $\mathrm{Fe}-\mathrm{Al}-\mathrm{Ni}$ alloys exhibiting $\sigma_{\mathrm{y}}>$ $1 \mathrm{GPa}$ and $Q^{-1}{ }_{\max }>0.032$; at room temperature, $f=1 \mathrm{~Hz}$ and $\varepsilon \approx 1 \times 10^{-4}$.

that of $\mathrm{Fe}-23.0 \mathrm{Al}$ binary alloys.

\section{Discussion}

In the present study, the effect of $\mathrm{Ni}$ addition on the strength and damping capacity of $\mathrm{Fe}-\mathrm{Al}-\mathrm{Ni}$ alloys was examined. Appropriate amounts of $\mathrm{Ni}$ doping were found to be effective in the increase in both $\sigma_{\mathrm{y}}$ and $Q^{-1}$. In particular, $\sigma_{\mathrm{y}}>1 \mathrm{GPa}$ and $Q^{-1}>0.032$ (specific damping index $>20 \%$ ) which are requirements for the automobile application under strong vibration could be achieved by optimizing the amount of Ni doping, as shown in Fig. 9. However, it should be noted that the high $Q^{-1}$ above 0.032 could be obtained only at limited strain amplitude (Fig. 5). Thus, further study is needed for the automobile application. In addition, the compositions of the alloys which showed high $\sigma_{\mathrm{y}}$ and $Q^{-1}$ are present in the $\alpha-\beta^{\prime}$ two-phase field. This also means that the $\beta^{\prime}$-NiAl phase plays an important role in enhancing the strength and damping capacity of $\mathrm{Fe}-\mathrm{Al}-\mathrm{Ni}$ alloys. Therefore, the role of the $\beta^{\prime}-\mathrm{NiAl}$ on the strength and damping capacity were discussed. In addition, the deformation and damping mechanisms of $\mathrm{Fe}-\mathrm{Al}-\mathrm{Ni}$ alloys were also discussed.

\subsection{Strengthening Mechanism in $\mathbf{F e}-\mathbf{A l}-\mathbf{N i}$ Alloys}

It is well known that the primary slip system of B2-type $\mathrm{NiAl}$ is $\{110\}<001>$ while $<111>$ slip was only activated at loading axis in the vicinity of $<001>$ orientation. ${ }^{15)}$ It should also be noted that the critical resolved shear stress (CRSS) for $<111>$ slip is about six times higher than that of $\{110\}<001>$ slip. In $\mathrm{Fe}-\mathrm{Al}-\mathrm{Ni}$ alloys, the $\beta^{\prime}$-NiAl precipitates coherent with the $\alpha$ matrix were inevitably sheared by $<111>$ slip of the $\alpha-\mathrm{Fe}-\mathrm{Al}$ matrix. In fact, the $\beta^{\prime}$ precipitates were observed to be cut by dislocations of the $\alpha$ matrix, the results are published in elsewhere. If the $\beta^{\prime}$ precipitates are sheared by $<111>$ direction in $\mathrm{Fe}-\mathrm{Al}-\mathrm{Ni}$ alloys, the frictional stress of dislocations inside the precipitates abruptly increases due to the difference in CRSS between $<001>$ and $<111>$ slips. Hence, the formation of the $\beta^{\prime}$ precipitates results in extreme hardening of $\mathrm{Fe}-\mathrm{Al}-\mathrm{Ni}$ alloys. It is also noted that precipitation-hardened stainless steels also contained the $\mathrm{NiAl}$ precipitates in the matrix composed of the martensite phase. In the stainless steels, the NiAl precipitates were also sheared by dislocations of the matrix phase, which would also lead to the hardening.

\subsection{High Damping Capacity in $\mathbf{F e}-\mathbf{A l}-\mathrm{Ni}$ Alloys}

It is well known that the damping mechanism of $\mathrm{Fe}-\mathrm{Al}$ binary alloys is based on the irreversible motion of magnetic domain walls during vibration. ${ }^{5-11)}$ Since the $Q^{-1}$ of Fe23.0Al-6.0Ni alloys shows low values under magnetic field, the magneto-mechanical damping seems to appear. It is also noted that the $\lambda_{\mathrm{m}}$ of the alloys showed higher values compared with $\mathrm{Fe}-23.0 \mathrm{Al}$ binary alloys as shown in Fig. 8. The $Q^{-1}$ based on magneto-mechanical damping was proposed by Kornetzki et al. ${ }^{15)}$ and is given by,

$$
Q^{-1}=3 \times 10^{15} \frac{\nu\left|\lambda_{\mathrm{m}}\right|^{3} E^{2}}{\pi I_{\mathrm{s}}^{3}} \varepsilon
$$

where $v$ is the magnetic Rayleigh constant, $\lambda_{\mathrm{m}}$ is the average saturation magnetostriction, $E$ is the Young's modulus, $I_{\mathrm{s}}$ is the saturation magnetization and $\varepsilon$ is the applied strain. From Eq. (2), the $Q^{-1}$ is strongly dependent on $\lambda_{\mathrm{m}}$. Thus, high $\lambda_{\mathrm{m}}$ in $\mathrm{Fe}-\mathrm{Al}-\mathrm{Ni}$ alloys with appropriate amount of $\mathrm{Ni}$ resulted in higher $Q^{-1}$.

It is also interesting to note that high $Q^{-1}$ above 0.032 could also be obtained at optimum chemical compositions, as shown in Fig. 9. The chemical composition of the $\alpha$-FeAl matrix varied accompanied by the precipitation of the $\beta^{\prime}$ $\mathrm{NiAl}$ phase. In other words, Al concentration in the $\alpha$ matrix decreased associated with the $\beta^{\prime}$ precipitation. For instance, if the $\beta^{\prime}$ phase precipitates in $\mathrm{Fe}-23.0 \mathrm{Al}-6.0 \mathrm{Ni}$ alloys, $\mathrm{Al}$ content of the $\alpha$ matrix would be 17 at $\%$. It is well known that superior damping capacity with high $Q^{-1}$ can be obtained at around 16-17 at\% $\mathrm{Al}$ in $\mathrm{Fe}-\mathrm{Al}$ binary alloys. ${ }^{5,6}$ In fact, $\mathrm{Fe}-17.0 \mathrm{Al}$ binary and $\mathrm{Fe}-23.0 \mathrm{Al}-6.0 \mathrm{Ni}$ ternary alloys showed similar damping properties. Thus, it is reasonable that the $\alpha$ matrix and $\beta^{\prime}$ precipitates acted as a high damping and high strength phases, respectively. Therefore, in association with the $\beta^{\prime}$ precipitation, the $\mathrm{Al}$ concentration in the $\alpha$ matrix became favorable for damping properties, resulting in high $Q^{-1}$ in $\mathrm{Fe}-\mathrm{Al}-\mathrm{Ni}$ alloys. Moreover, the $\beta^{\prime}$ precipitates may not interfere the motion of magnetic domain walls leading to magneto-mechanical damping if the amount of the $\beta^{\prime}$ phase is small. This is reasonable assumption because the misfit strain between the $\alpha$ and $\beta^{\prime}$ phases was small. However, in Fe-23.0Al-10.0Ni alloys, the volume fraction of the $\beta^{\prime}$ precipitates which shows a paramagnetism was so high that the magneto-mechanical damping was hindered by the precipitates (Fig. 6). Thus, Fe-Al-Ni alloys with the appropriate amount of the $\beta^{\prime}-\mathrm{NiAl}$ phase could exhibit both high $\sigma_{\mathrm{y}}$ and high $Q^{-1}$.

\section{Conclusions}

The deformation and damping behavior of Ni-doped Fe$\mathrm{Al}$ alloys were examined focusing on the $\beta^{\prime}$-NiAl precipitates. The following conclusions were reached.

(1) Fe-Al-Ni alloys with appropriate chemical compositions exhibited $\sigma_{\mathrm{y}}>1 \mathrm{GPa}$ and $Q^{-1}>0.032$.

(2) The $\beta^{\prime}$-NiAl precipitates significantly strengthened $\mathrm{Fe}-\mathrm{Al}-\mathrm{Ni}$ alloys owing to the difference in primary slip systems between the $\beta^{\prime}$ precipitates and the $\alpha$ matrix.

(3) The vibration attenuation in $\mathrm{Fe}-\mathrm{Al}-\mathrm{Ni}$ alloys was considered to be based on magneto-mechanical damping.

(4) Associated with the precipitation of the $\beta^{\prime}-\mathrm{NiAl}$ phase, Al concentration of the $\alpha$ matrix became favorable 
for magneto-mechanical damping, which resulted in high $Q^{-1}$.

\section{Acknowledgements}

The author (H.Y. Yasuda) would like to thank the ISIJ Research Promotion Grant for supporting this research. This work was also supported by the Priority Assistance for the Formation of Worldwide Renowned Centers of Research The Global COE Program (Project: Center of Excellence for Advanced Structural and Functional Materials Design) from the MEXT, Japan. The author would also like to thank Prof. Yuichiro Koizumi for supporting the measurement of internal friction under magnetic field.

\section{REFERENCES}

1) I. G. Ritchie and Z. L. Pan: Metall. Trans. A, 22 (1991), 607.

2) T. Sakaguchi: Kinzoku, 74 (2004), 277 (in Japanese).
3) M. Dolce and D. Cardone: Int. J. Mech. Sci., 43 (2001), 2631.

4) M. Dolce and D. Cardone: Int. J. Mech. Sci., 43 (2001), 2657.

5) I. S. Golovin, H. Neuhäuser, A. Riviere and A. Strahl: Intermetallics, 12 (2004), 125.

6) K. Mizuuchi, Y. Okanda and S. Motogi: Sci. Industry, 64 (1990), 417 (in Japanese).

7) T. Yamada, T. Takamura, S. Hashizume, T. Odake, T. Omori and K. Hahhori: NKK Tech. Rep., 137 (1991), 18.

8) D. P. Sagradi, M. Sagradi, A. Karimi and J. L. Martin: Scr. Mater., 39 (1998), 131.

9) Z. C. Zhou, J. N. Wei and F. S. Han: Phys. Status Solidi (a), 191 (2002), 89.

10) Y. I. Seo, B. H. Lee, Y. D. Kim and K. H. Lee: Mater. Sci. Eng. A, 431 (2006), 80.

11) X. Y. Gang, L. Ning, S. B. Luo and H. H. Xin: Mater. Sci. Eng. A, 447 (2007), 163.

12) H. Y. Yasuda, K. Fukushima, Y. Koizumi, Y. Minamino and Y. Umakoshi: ISIJ Int., 49 (2009), 1630.

13) V. G. Rivlin and G. V. Raynor: Int. Metals Rev., 25 (1980), 79.

14) V. M. Kornetzki: Z. Phys., 121 (1943), 560.

15) D. B. Miracle: Acta Metall. Mater., 41 (1993), 649. 